\title{
LAYOUT OF THE ABSORBERS FOR THE SYNCHROTRON LIGHT SOURCE ANKA
}

\author{
S.Hermle, D.Einfeld, E.Huttel \\ Forschungszentrum Karlsruhe, ANKA, P.O. 3640 ,76021 Karlsruhe, Germany \\ G. Heidenreich, Paul Scherrer Institut, 5232 Villigen, Switzerland
}

\section{Abstract}

The $2.5 \mathrm{GeV}$ Synchrotron Light Source ANKA is now under construction at the Research Center in Karlsruhe. For a designed current of $400 \mathrm{~mA}$, a power of $250 \mathrm{~kW}$ is radiated by the circulating e-beam in the 16 dipole magnets. $90 \%$ of the synchrotron radiation (SR) is absorbed by the 32 crotch absorbers in the dipole and the adjacent ante chamber, the remaining $10 \%$ by distributed absorbers in the straight chambers. The power per length is up to $50 \mathrm{~W} / \mathrm{mm}$ for the crotch and $2 \mathrm{~W} / \mathrm{mm}$ for the distributed absorbers. A special design was needed for the crotch absorbers due to the limited space. The final design is optimized for reduced thermal stress in order to increase the number of maximum possible cycles. The temperature distribution and the stresses were calculated with the finite element program ANSYS[1]. The maximum temperature is $270{ }^{\circ} \mathrm{C}$, the maximum strain $0.13 \%$.The achieved strain will be small enough in order to sustain more than $10^{4}$ cycles, the expected lifetime of the absorbers. The SR entering the beam lines $(15 \mathrm{mrad})$ will be absorbed either by one moveable absorber before the first valve or by the movable radiation protection shutter close to the shielding wall. The power per length is $13 \mathrm{~W} / \mathrm{mm}$, respectively $7 \mathrm{~W} / \mathrm{mm}$.

\section{INTRODUCTION}

The total power radiated by a Synchrotron Radiation
Source from the bending magnets is given by [2]:

$$
\mathrm{P}[\mathrm{kW}]=88.6 \mathrm{E}[\mathrm{GeV}]^{4} \mathrm{I}[\mathrm{A}] / \mathrm{r}[\mathrm{m}]
$$

For the design parameter of ANKA : E: $2.5 \mathrm{GeV}$, I: $0.4 \mathrm{~A}$ and $\mathrm{r}: 5.559 \mathrm{~m}$ the radiated power is: $\mathrm{P}=250 \mathrm{~kW}$.

The vertical power distribution has a FWHM of $0.7 \mathrm{~mm}$ at a distance of $1 \mathrm{~m}$ from the source point [3].

In Fig. 1 the absorbers of the dipole vacuum chambers and the adjacent sextupole section are shown. The maximum power loads and temperatures of the different absorbers are summarised in Table 1.

$90 \%$ of the synchrotron radiation will be absorbed by crotch absorbers ((1) in Fig.1) in the ante chambers of the dipole and the adjacent quadrupole / sextupole chamber. The first crotch absorber covers the radiation from $0^{\circ}$ to $11^{\circ}$ of a dipole, corresponding to a heat load of $8 \mathrm{~kW}$, the second crotch absorber the radiation up to $21^{\circ}$. The power per length at the crotch absorbers increases from 20 close to the flange to 50 $\mathrm{W} / \mathrm{mm}$ at the top due to the different distance from the source point.

$10 \%$ of the synchrotron power will be absorbed by distributed absorbers $((2,3)$ in Fig.1) which are part of the outer side of the vacuum chamber in the straight vacuum chambers. The inner side of the distributed absorber of the first vacuum chamber behind the dipole ((2) in Fig.1) has a copper plating in order to distribute the higher heat

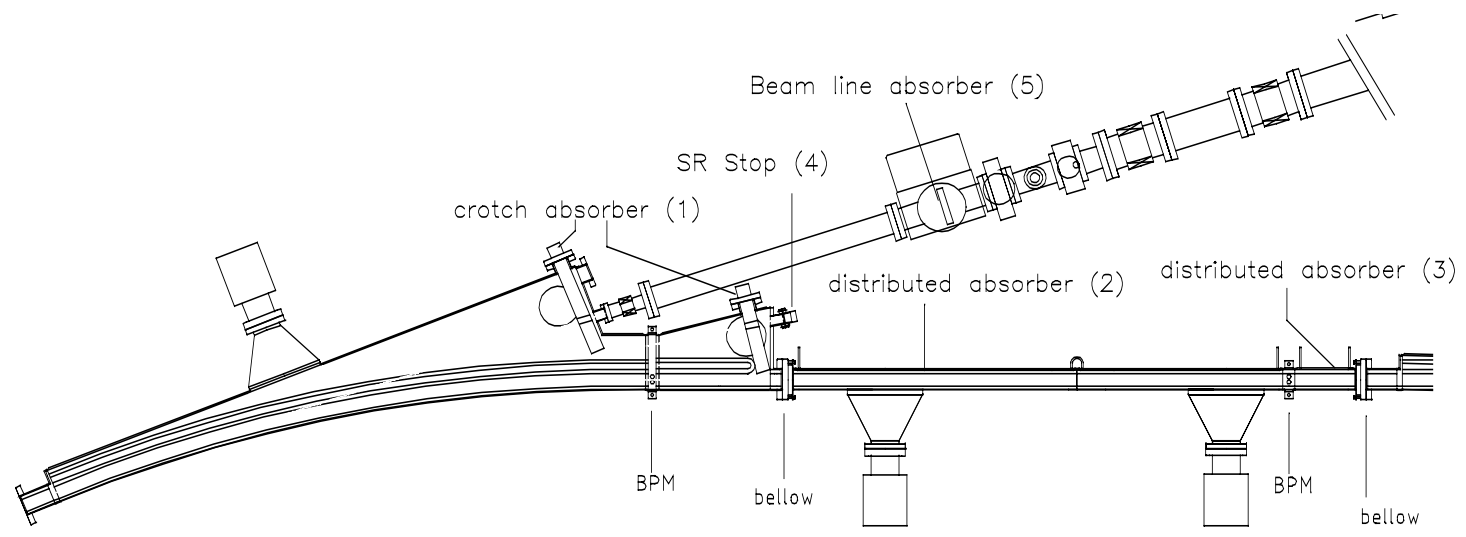

Figure 1: Distribution and lay out of the absorbers at the Synchrotron Radiation Source ANKA. 


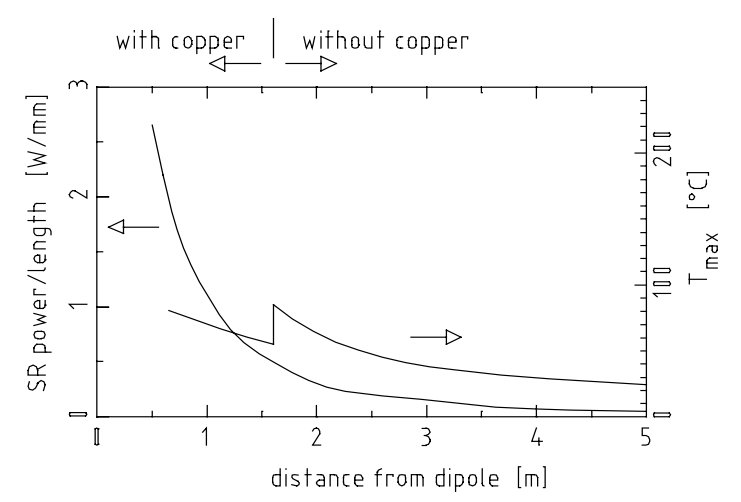

Figure 2: Power and temperature distribution of the distributed absorbers.

load. The power per length decreases as a function of the distance from the source point from $2 \mathrm{~W} / \mathrm{mm}$ for the copper plated and $0.4 \mathrm{~W} / \mathrm{mm}$ for the stainless steel type. The power and temperature distribution is given in Fig. 2.

The SR entering the beam lines $(15 \mathrm{mrad})$ will be absorbed either by a moveable absorber ((5) in Fig.1) before the first valve or by the movable radiation protection shutter close to the shielding wall. The power density is $13 \mathrm{~W} / \mathrm{mm}$, respectively $7 \mathrm{~W} / \mathrm{mm}$. Parts of the SR exit ports where a front end is not installed are equipped with a cooled end flange ((4) in Fig.1). It's power per length is $44 \mathrm{~W} / \mathrm{mm}$.

\section{THE CROTCH ABSORBERS}

In Fig. 4 the design of the lumped absorber is shown. Due to the inner height of the vacuum chamber of $32 \mathrm{~mm}$ the vertical size of the absorber is limited to $31 \mathrm{~mm}$. Cooling is done by four $9 \mathrm{~mm}$ pin holes with a $6 \times 0.5 \mathrm{~mm}$ tube for the incoming water. A wire is wound around the inner tube in order to enhance the heat transfer. A thermal conductivity of $380 \mathrm{~W} / \mathrm{Km}$ for copper and a heat transfer coefficient of $12 \mathrm{~kW} / \mathrm{Km}^{2}$ for $3 \mathrm{~m} / \mathrm{s}$ water velocity was used for the calculations. The temperature distribution for the highest load are also given in Fig. 4. The maximum temperature is $270^{\circ} \mathrm{C}$. The highest temperature at the cooling canal is $120^{\circ} \mathrm{C}$. The temperature of the water

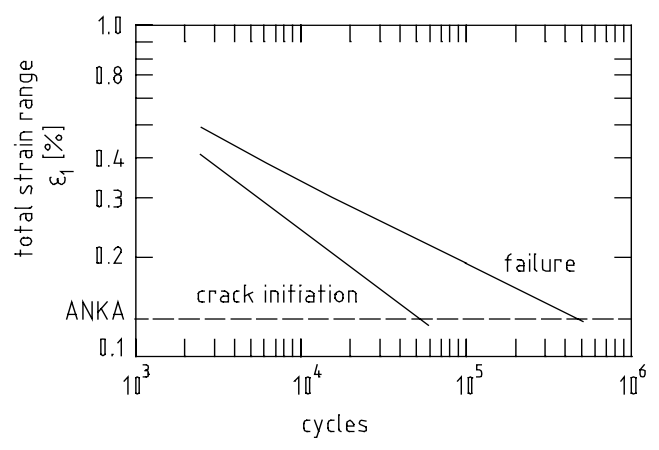

Figure 3: Fatigue behavior of OFHC copper as a function of strain and cycles.

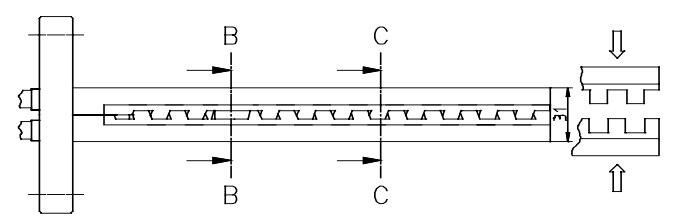

$$
\mathrm{B}-\mathrm{B} \quad \mathrm{C}-\mathrm{C}
$$
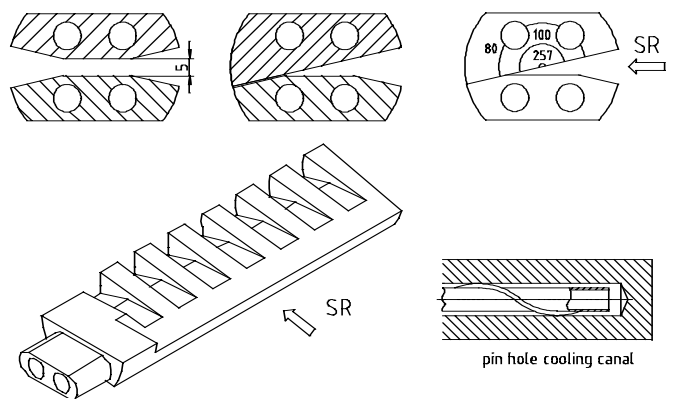

Figure 4: Final design of the crotch absorber.

should be kept below boiling point. But since the inlet water is pressurised (about 3 bar at the top of the absorber) the boiling temperature is above $100{ }^{\circ} \mathrm{C}\left(10^{\circ} \mathrm{C}\right.$ per bar).

Parts at higher temperature $\left(\mathrm{T}_{\mathrm{m}}\right)$ tend to expand by a strain $\varepsilon=\alpha\left(\mathrm{T}_{\mathrm{m}}-\mathrm{T}_{\mathrm{b}}\right)$ which is hindered by the bulk of the material which is at the lower bulk temperature $\left(\mathrm{T}_{\mathrm{b}}\right) . \alpha$ is the thermal expansion coefficient (For copper $\alpha=1.710^{5}$ $1 / \mathrm{K}$.)

The cyclic temperature changes and the corresponding strains lead to fatigue of the material which can lead to failure. Fig. 3 shows the failure of OFHC copper as a function of the cycles and strain [4]. Since more than 10000 cycles should be guarantied the strain should be less than $0.2 \%$.

In order to reduce the strain, the absorber is split into two halves with a comb like structure each with two cooling canals. The comb structure of the upper and the lower part fit together with $0.1 \mathrm{~mm}$ separation. Due to an angle between the synchrotron radiation and the normal of the absorber no radiation can pass the absorber. Since the synchrotron radiation now hits alternating small sections of the upper or lower part of the absorber which are slightly separated, the hot sections can expand slightly and thus the maximum stress is reduced from 0.27 to $0.13 \%$.

\section{DISTRIBUTED ABSORBER}

The cross sections of the straight vacuum chamber are shown in Fig. 5. The synchrotron radiation hits the vacuum chamber which is water cooled from the outside. But since the vacuum chamber is generally built from stainless steel having a low thermal conductivity of $16 \mathrm{~W} /$ $\mathrm{Km}$ the wall temperature would become too high close to the dipole magnet. Thus the inner side of the vacuum chamber of the section which is close to the magnet is plated by $3 \mathrm{~mm}$ copper, which will distribute the heat load before it is transferred through $1 \mathrm{~mm}$ stainless steel to the 


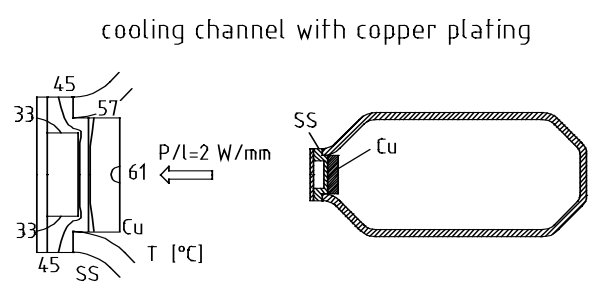

cooling channel without copper plating
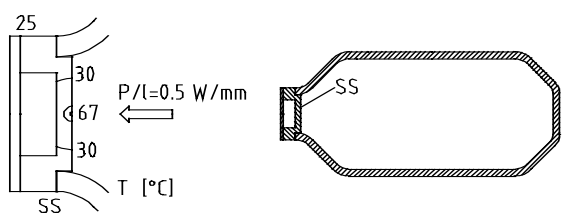

Figure 5: Distributed absorber and their temperature distribution.

cooling water. Fig.5 also shows maximum temperature profiles for both types of distributed absorbers. The copper plating of the stainless steel was done by explosion bonding. Each copper stainless steel compound was controlled with ultra sonic for proper bonding. Compounds with improper bonding areas larger than 0.5 mm have been excluded.

\section{FRONT END ABSORBER}

Each synchrotron beam line is equipped with an all metal gate valve and a moveable absorber in front of it in order to protect the closed valve. Since this absorber has a distance of $2.5 \mathrm{~m}$ from the source point the power density is smaller compared to the absorbers in the dipole. Thus a copper plate with a copper tube brazed in it is sufficient as an absorber. The design is shown in Fig.6 together with the temperature distribution.

Parts of the SR beam ports which are not yet equipped with a front end are closed with a cooled end flange. This consists of conical block made of OFHC

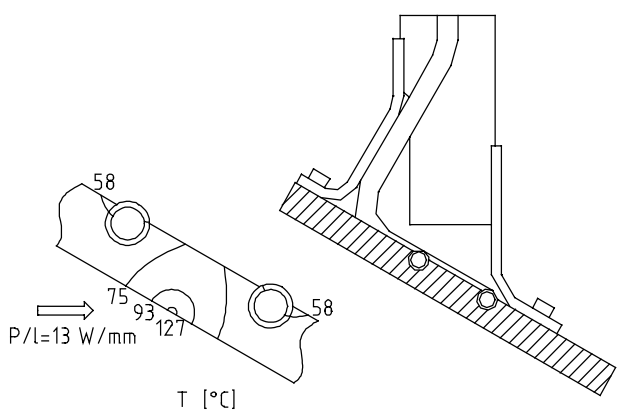

Figure 6: Absorber in the Frontends.

copper with a spiral cooling canal on it. The design and the temperature distribution are shown in Fig. 7.

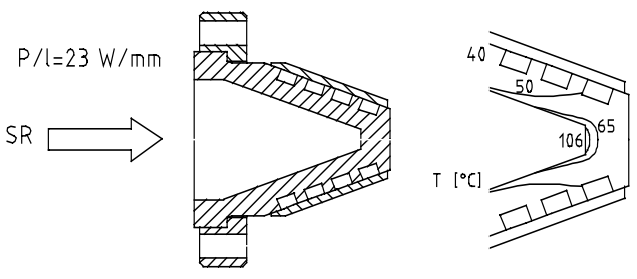

Figure 7: Design and temperature distribution of the cooled end flange.

\section{REFERENCES}

[1] ANSYS, Swanson Analysis Systems,Inc.

[2] H.Wiedemann: Particle Accelerator Physics I, Springer Verlag.

[3] H.Wiedemann: Particle Accelerator Physics II, Springer Verlag.

[4] K.C.Liu and C.M.Loring, Jour.Nucl.Mat.122(1984)783

Table 1: Power and Temperature of the different absorbers, dps refers to a dipole followed by a sextupole section, dqs for a dipole followed by a quadruple doublet.

\begin{tabular}{|l|c|c|c|c|c|c|c|c|c|}
\hline absorber & $\begin{array}{l}\text { Angle } \\
{\left[{ }^{\circ}\right]}\end{array}$ & $\begin{array}{l}\mathrm{D} \text { source } \\
{[\mathrm{m}]}\end{array}$ & $\begin{array}{l}\mathrm{P} \\
{[\mathrm{kW}]}\end{array}$ & $\begin{array}{l}\mathrm{P} / \mathrm{l} \\
{[\mathrm{W} / \mathrm{mm}]}\end{array}$ & $\begin{array}{l}\mathrm{P} / \mathrm{a} \\
{\left[\mathrm{W} / \mathrm{mm}^{2}\right]}\end{array}$ & $\begin{array}{l}\mathrm{V}_{\text {water }} \\
{[\mathrm{m} / \mathrm{s}]}\end{array}$ & $\begin{array}{l}\text { Flow } \\
{[\mathrm{l} / \mathrm{min}]}\end{array}$ & $\begin{array}{l}\mathrm{T}_{\max } \\
{\left[{ }^{\circ} \mathrm{C}\right]}\end{array}$ & $\begin{array}{l}\mathrm{T}_{\text {bulk }} \\
{\left[{ }^{\circ} \mathrm{C}\right]}\end{array}$ \\
\hline 1 crotch dps & 10.5 & $2.1-1.1$ & 7.5 & $20-40$ & $7-24$ & 3 & 16 & 190 & 80 \\
\hline 2 crotch dps & 10 & $1.7-0.8$ & 6.5 & $25-50$ & $10-50$ & 3 & 16 & 270 & 120 \\
\hline Distr. copper & 1.6 & $0.9-2.8$ & 1.3 & $2-0.2$ & $7-0.2$ & 2 & 3 & 60 & 40 \\
\hline 1. crotch dpq & 11.5 & $2.1-0.9$ & 8.5 & $20-40$ & $7-32$ & 3 & 16 & 220 & 100 \\
\hline 2. crotch dpq & 8.5 & $1.7-0.9$ & 5.9 & $23-40$ & $9-32$ & 3 & 16 & 220 & 100 \\
\hline Distr. copper & 0.7 & $1.1-1.8$ & .6 & $1.5-0.5$ & $4-0.9$ & 2 & 3 & 60 & 40 \\
\hline Distr. steel & 1 & $1.8-8$ & .6 & 0.4 & $0.8-0.01$ & 2 & 3 & 70 & 40 \\
\hline Front end 1 & 1 & 3 & .8 & 13 & 10 & 2 & 3 & 130 & 70 \\
\hline Front end 2 & 1 & 6 & .8 & 7 & 4 & 2 & 3 & 110 & 50 \\
\hline flange & 1 & 1.7 & .8 & 23 & 44 & 2 & 3 & 170 & 80 \\
\hline
\end{tabular}

